\title{
3D fossil reconstruction related to the publication: Body shape and life style of the extinct rodent Canariomys bravoi from Tenerife, Canary Islands
}

\author{
MICHAUX J. ${ }^{a}$, HAUTIER L. ${ }^{a}$, HUTTERER, R. ${ }^{b}$, LEBRUN R. ${ }^{a *}$, GUY F. ${ }^{c}$ and GARCIA-TALAVERA F. ${ }^{\mathrm{d}}$ \\ ${ }^{a}$ Laboratoire de Paléontologie, Institut des Sciences de l'Évolution de Montpellier (ISE-M, UMR 5554, CNRS, UM2, IRD), c.c. \\ 064, Université Montpellier 2, place Eugène Bataillon, F-34095 Montpellier Cedex 05, France \\ ${ }^{\mathrm{b}}$ Zoologisches Forschungsmuseum Alexander Koenig, Adenauerallee 160, 53113 Bonn, Germany \\ ' Université de Poitiers - UFR SFA, iPHEP UMR CNRS 7262, Bât B35 - TSA 51106, 6 rue Michel brunet, 86073, Poitiers Cedex \\ 9, France \\ ${ }^{\mathrm{d}}$ Museo de Ciencias Naturales de Tenerife, 38080 Santa Cruz de Tenerife, Islas Canarias, Spain \\ * corresponding author: renaud.lebrun@univ-montp2.fr
}

\begin{abstract}
This contribution contains the 3D reconstruction of Canariomys bravoi, described and figured in the following publication: Michaux J., Hautier L., Hutterer R., Lebrun R., Guy F., García-Talavera F., 2012 : Body shape and life style of the extinct rodent Canariomys bravoi (Mammalia, Murinae) from Tenerife, Canary Islands (Spain). Comptes Rendus Palevol 11 (7), $485-494$. doi:10.1016/j.crpv.2012.06.004
\end{abstract}

Key words: Canari Islands, Fossil reconstruction, Insularity, Rodentia

Submitted 12.12.2014, Accepted 05.01.2015. doi : 10.18563/m3.1.1.e3

(C) Copyright Renaud Lebrun January 2015

\section{TECHNICAL AND SPECIMEN-RELATED PARAMETERS}

\begin{tabular}{|l|l|l|}
\hline Specimen inventory number & TFMCV872 & TFMCV873 \\
\hline Species & Canariomys bravoi & Canariomys bravoi \\
\hline Repository institution & $\begin{array}{l}\text { Museo de la Naturaleza y el Hombre, } \\
\text { Santa Cruz }\end{array}$ & $\begin{array}{l}\text { Museo de la Naturaleza y el Hombre, } \\
\text { Santa Cruz }\end{array}$ \\
\hline 3D data acquisition institution & Université de Poitiers, France & ISE-M, Université Montpellier 2, France \\
\hline 3D data acquisition method & X-ray $\mu$ CT & X-ray $\mu$ CT \\
\hline 3D data acquisition facility model & Viscom X8050-16 & SkyScan 1076 \\
\hline 3D data acquisition operator & Franck Guy & Renaud Lebrun \\
\hline Voxel size of original dataset & 0,079 mm & 0,036 mm \\
\hline Author of derived 3D surface model & Renaud Lebrun and Mikaël Antioco & Renaud Lebrun and Mikaël Antioco \\
\hline Model ID & M3\#6 TFMCV872-873 & M3\#6 TFMCV872-873 \\
\hline
\end{tabular}

\section{METHODS}

The present three-dimensional reconstruction of the skeleton of the Holocene giant rat of Tenerife (Canary Islands, Spain) was obtained by computerized microtomography reconstruction. Two distinct specimens were used in this reconstruction, TFMCV872 and TFMCV873 (Museo de la Naturaleza y el Hombre, Santa Cruz). TFMCVF872 is an almost complete but disarticulated skeleton of $C$. bravoi. As the mandibles and the cranium of this specimen were not well preserved, a complete skull of C. bravoi (TFMCVF873) was added to this reconstruction.

All the bones were extracted within a "labelfield" module of AVIZO 6.3, using the segmentation threshold selection tool. The $3 \mathrm{D}$ model is provided in a series of .vtk format, and the whole reconstruction can be opened with ISE-MeshTools (Lebrun, 2014).

\section{DISCUSSION}

Murinae rodents observed by Owen (1853) always possess a total amount of 19 thoraco-lumbar vertebrae, most often divided in 13 thoracic and 6 lumbar vertebrae (he also observed at least one specimen of Rattus norvegicus possessing 12 thoracic and 7 lumbar vertebrae). This number of 19 thoraco-lumbar vertebrae is observed very often in mammals and is thought to be a plesiomorphic condition for eutherians and metatherians mammals (for a review, see for instance Sánchez-Villagra et al., 2007). The present fossil of $C$. bravoi exhibits a number of 17 thoraco-lumbar vertebrae, so it is likely that 2 vertebrae (either 1 thoracic and 1 lumbar, or 2 lumbar) are missing. Furthermore, the number of caudal vertebrae in Murinae rodents observed by Owen (1853) is often greater than the 21 presented in this reconstruction. The present reconstruction of 
Canariomys bravoi does not take into account these potentially missing thoraco-lumbar and caudal vertebrae.

\section{ACKNOWLEDGEMENTS}

We are grateful to María Esther Martín González, curator of the Museo de la Naturaleza y el Hombre, Santa Cruz, for her enthusiasm regarding the diffusion of the present model. Data presented in this work were produced through the technical facilities of the MRI platform and of the labEx CeMEB, and at the Centre de Microtomography of the University of Poitiers. The present work developed results of a preliminary study initiated by Mikaël Antioco during the academic year 2010-2011, at the Paleontology Department, University of Montpellier-2. This is ISE-M publication 2015-004.

\section{BIBLIOGRAPHY}

Lebrun R., 2014. ISE-MeshTools, a 3D interactive fossil reconstruction freeware. 12th Annual Meeting of EAVP, Torino, Italy.

Michaux J., Hautier L., Hutterer R., Lebrun R., Guy F., GarcíaTalavera F., 2012. Body shape and life style of the extinct rodent Canariomys bravoi (Mammalia, Murinae) from Tenerife, Canary Islands (Spain). Comptes Rendus Palevol 11, 485-494.

http://dx.doi.org/10.1016/j.crpv.2012.06.004

Owen R., 1853. Descriptive Catalogue of the Osteological Series contained in the Museum of the Royal College of Surgeons of England. http://dx.doi.org/10.5962/bhl.title.23768

Sánchez-Villagra M.R., Narita Y., Kuratani S., 2007. Thoracolumbar vertebral number: the first skeletal synapomorphy for afrotherian mammals. Systematics and Biodiversity 5 (1), 1-7.

http://dx.doi.org/10.1017/S1477200006002258 